\title{
Drug-eluting stents versus coronary artery bypass grafting for the treatment of coronary artery disease: A meta-analysis of randomized and nonrandomized studies
}

\author{
Tristan D. Yan, BSc(Med), MBBS, PhD, ${ }^{\mathrm{a}, \mathrm{b}}$ Ratnasari Padang, MBBS, ${ }^{\mathrm{c}}$ Chin Poh, ${ }^{\mathrm{a}}$ \\ Christopher Cao, BSc(Med), MBBS, ${ }^{\mathrm{a}, \mathrm{b}}$ Michael K. Wilson, MBBS, ${ }^{\mathrm{a}, \mathrm{b}}$ Paul G. Bannon, MBBS, PhD, ${ }^{\mathrm{a}, \mathrm{b}}$ and \\ Michael P. Vallely, MBBS, $\mathrm{PhD}^{\mathrm{a}, \mathrm{b}}$
}

\begin{abstract}
Background: We performed the present systematic review and meta-analysis of randomized and nonrandomized comparative studies in an attempt to compare the safety and efficacy of drug-eluting stents with coronary artery bypass grafting for patients with coronary artery disease.
\end{abstract}

\begin{abstract}
Methods: Twenty-five eligible comparative studies (1 randomized and 24 nonrandomized) were assessed. Two reviewers independently appraised each study. Meta-analysis was performed by combining the results of reported incidence of morbidity, mortality, and repeat revascularization. The relative risk was used as a summary statistic.

Results: In these 25 studies 34,278 patients were compared, of whom 18,538 received drug-eluting stents and 15,740 underwent coronary artery bypass grafting. It must be acknowledged that this comparison represented a selected group of patients who received drug-eluting stents or underwent coronary artery bypass grafting. The accumulative incidences of all-cause mortality at 12 months $(4.5 \%$ vs $4.0 \%, P=.92)$ and 24 months $(6.2 \%$ vs $8.4 \%, P=.27)$ and 30 -day myocardial infarction $(1.4 \% \mathrm{vs} 2.0 \%, P=.60)$ were similar, respectively, between the drug-eluting stent and coronary artery bypass grafting groups. Drug-eluting stents were associated with lower rates of all-cause mortality at 30 days $(0.9 \%$ vs $2.3 \%, P<.001)$, stroke $(0.4 \%$ vs $1.7 \%, P<.001)$, and 30 -day major adverse cardiac and cerebrovascular events $(3.6 \%$ vs $5.5 \%, P<.04)$. However, the coronary artery bypass grafting group had a lower incidence of postprocedural myocardial infarction $(5.5 \%$ vs $4.7 \%, P=.03)$, repeat revascularization $(22.2 \%$ vs $4.1 \%, P<.001)$, and 12 -month major adverse cardiac and cerebrovascular events $(16.7 \%$ vs $10.5 \%, P<.001)$. Subgroup analysis of patients with multivessel coronary artery disease showed similar results.
\end{abstract}

Conclusions: Drug-eluting stents are associated with less periprocedural risks but a higher incidence of postprocedural myocardial infarction, repeat revascularization, and 12-month major adverse cardiac and cerebrovascular events compared with coronary artery bypass grafting. (J Thorac Cardiovasc Surg 2011;141:1134-44)

Earn CME credits at

http://cme.ctsnetjournals.org

Coronary artery bypass grafting $(\mathrm{CABG})$ and percutaneous coronary intervention $(\mathrm{PCI})$ are alternative revascularization techniques for symptomatic patients with coronary artery disease. ${ }^{1}$ Increased experience with PCI and improved

From the Baird Institute for Applied Heart and Lung Surgical Research, ${ }^{\mathrm{a}}$ Newtown, Australia; and the Departments of Cardiothoracic Surgery ${ }^{b}$ and Cardiology, University of Sydney, Royal Prince Alfred Hospital, Sydney, Australia.

Disclosures: Authors have nothing to disclose with regard to commercial support.

Received for publication Nov 26, 2009; revisions received June 22, 2010; accepted for publication July 6, 2010; available ahead of print Dec 20, 2010.

Address for reprints: Tristan D. Yan, BSc(Med), MBBS, PhD, University of Sydney, Department of Cardiothoracic Surgery, Royal Prince Alfred Hospital, Sydney,

Australia (E-mail: tristan.yan@hotmail.com).

0022-5223/\$36.00

Copyright $\Subset 2011$ Published by Elsevier Inc. on behalf of The American Association for Thoracic Surgery

doi: $10.1016 /$ j.jtcvs.2010.07.001 technological advent have expanded its use in patients with severe coronary artery disease and complex anatomic lesions. A meta-analysis by Mercado and colleagues ${ }^{2}$ comparing randomized controlled trials (RCTs) of PCI with bare metal stents (BMSs) versus CABG demonstrated similar degrees of protection against death, myocardial infarction, and stroke for patients with multivessel coronary artery disease at 1 year after the initial procedure. However, repeat revascularization procedures remained more likely after use of BMSs. A subsequent meta-analysis by Daemen and coworkers ${ }^{3}$ comparing RCTs on the long-term outcomes between PCI with BMSs and CABG (the Stent of Surgery trial, the Arterial Revascularization Therapies Study, Edstudio Randomizado Argentino de Angioplastia vs Cirugia II, and the Medicine, Angioplasty or Surgery Study II) indicated that BMSs were associated with a long-term safety profile similar to that of CABG but also reinforced higher revascularization and major adverse cardiac and cerebrovascular events (MACCEs) in the BMS group. ${ }^{3}$

Drug-eluting stents (DES) demonstrate similar rates of death and myocardial infarction but reduced rates of repeat 


$$
\begin{aligned}
& \text { Abbreviations and Acronyms } \\
& \begin{aligned}
\text { BMS } & =\text { bare metal stent } \\
\text { CABG } & =\text { coronary artery bypass grafting } \\
\text { CI } & =\text { confidence interval } \\
\text { DES } & =\text { drug-eluting stent } \\
\text { MACCE } & =\text { major adverse cardiac and } \\
& \text { cerebrovascular event } \\
\text { PCI } & =\text { percutaneous coronary intervention } \\
\text { RCT } & =\text { randomized controlled trial } \\
\text { RR } & =\text { relative risk } \\
\text { SYNTAX } & =\text { Synergy Between PCI with Taxus } \\
& \text { and Cardiac Surgery }
\end{aligned}
\end{aligned}
$$

revascularization compared with BMSs, ${ }^{4}$ thus increasing the percentage of patients with multivessel disease treated with PCI. However, recent data suggested a higher rate of thrombotic occlusion with DESs than BMSs. ${ }^{5}$ The recent Synergy Between PCI with Taxus and Cardiac Surgery (SYNTAX) trial compared DESs versus CABG in patients with triple- vessel or left main coronary artery disease. ${ }^{6}$ This RCT demonstrated that at 12 months the rates of death and myocardial infarction were similar between the 2 groups, but DESs were associated with a significantly higher rate of MACCEs $(17.8 \%$ vs $12.4 \%, P=.002)$ and lower rate of stroke $(0.6 \%$ vs $2.2 \%, P=.003)$. As is generally true with RCTs, the study population is predefined and hence subject to trial design bias. We performed the present systematic review and meta-analysis of the randomized and nonrandomized comparative studies in an attempt to assess the safety and efficacy of DESs versus CABG with the current clinical evidence.

\begin{tabular}{|c|c|c|c|c|c|c|c|c|c|}
\hline \multirow[b]{2}{*}{ Reference } & \multirow[b]{2}{*}{ Study design } & \multirow[b]{2}{*}{ Study population } & \multirow[b]{2}{*}{ Study period } & \multicolumn{2}{|c|}{ No. of patients } & \multicolumn{2}{|c|}{$\begin{array}{c}\text { Age of cohort } \\
(\text { mean } \pm \text { SD })\end{array}$} & \multicolumn{2}{|c|}{$\begin{array}{l}\text { Ejection fraction } \\
(\text { mean } \pm \text { SD })\end{array}$} \\
\hline & & & & DES & CABG & DES & CABG & DES & CABG \\
\hline Ben-Gal and coworkers ${ }^{9}$ & $\mathrm{OC}$ & DM & 2002-2005 & 86 & 86 & NA & NA & NA & NA \\
\hline Ben-Gal and coworkers ${ }^{10}$ & OC & LAD & $2002-2003$ & 83 & 83 & NA & NA & NA & NA \\
\hline Briguori and coworkers ${ }^{11}$ & OC & MVD, LAD, DM, OPCAB & 2002-2004 & 69 & 149 & $63 \pm 9$ & $66 \pm 9$ & $54 \pm 12$ & $53 \pm 9$ \\
\hline Cheng and coworkers ${ }^{12}$ & OC & LMCAD & $2000-2007$ & 94 & 216 & $68 \pm 10$ & $67 \pm 9$ & $56 \pm 17$ & $56 \pm 20$ \\
\hline Chieffo and coworkers ${ }^{13}$ & OC & LMCAD & 2002-2004 & 107 & 142 & $64 \pm 10$ & $68 \pm 10$ & $52 \pm 10$ & $52 \pm 11$ \\
\hline $\begin{array}{l}\text { Domínguez-Franco and } \\
\text { coworkers }{ }^{14}\end{array}$ & $\mathrm{OC}$ & MVD, LAD, DM & $2000-2004$ & 128 & 142 & 68 & 65 & $52 \pm 13$ & $54 \pm 14$ \\
\hline Gioia and coworkers ${ }^{15}$ & OC & LV dysfunction & 2002-2005 & 128 & 92 & $69 \pm 10$ & $68 \pm 10$ & $28 \pm 6$ & $27 \pm 8$ \\
\hline Hannan and coworkers ${ }^{16}$ & OC & MVD & 2003-2005 & 9963 & 7437 & $65 \pm 12$ & $66 \pm 11$ & NA & NA \\
\hline Hong and coworkers ${ }^{17}$ & OC & LAD & 2003 & 119 & 70 & $61 \pm 10$ & $61 \pm 10$ & $53 \pm 9$ & $52 \pm 9$ \\
\hline Javaid and coworkers ${ }^{18}$ & $\mathrm{OC}$ & MVD & NA & 979 & 701 & $66 \pm 11$ & $65 \pm 11$ & NA & NA \\
\hline Kukreja and coworkers ${ }^{19}$ & $\mathrm{OC}$ & MVD, LAD & $1997-2003$ & 289 & 206 & $63 \pm 10$ & $62 \pm 9$ & $59 \pm 12$ & $61 \pm 13$ \\
\hline White and coworkers ${ }^{20}$ & OC & LMCAD & 2003-2005 & 50 & 123 & $72 \pm 15$ & $70 \pm 10$ & $51 \pm 15$ & $52 \pm 10$ \\
\hline $\mathrm{Li}$ and coworkers ${ }^{21}$ & OC & MVD & 2004-2005 & 1834 & 1886 & $58 \pm 10$ & $61 \pm 9$ & NA & NA \\
\hline Mäkikallio and coworkers ${ }^{22}$ & OC & LMCAD & $2005-2007$ & 49 & 238 & $72 \pm 10$ & $70 \pm 9$ & $55 \pm 12$ & $54 \pm 11$ \\
\hline Moshkovitz and coworkers ${ }^{23}$ & OC & LAD, OPCAB & $2002-2003$ & 116 & 116 & NA & NA & NA & NA \\
\hline Palmerini and coworkers ${ }^{24}$ & OC & LMCAD & 2003-2006 & 98 & 161 & $81^{*}$ & $78 *$ & $50 *$ & $53 *$ \\
\hline Park and coworkers ${ }^{25}$ & OC & MVD & 2003-2005 & 1547 & 1495 & $62 \pm 10$ & $62 \pm 9$ & $59 \pm 9$ & $56 \pm 11$ \\
\hline Sanmartín and coworkers ${ }^{26}$ & OC & LMCAD & $2000-2005$ & 96 & 245 & $66 \pm 13$ & $66 \pm 10$ & NA & NA \\
\hline Serruys and coworkers ${ }^{6}$ & $\mathrm{RCT}$ & MVD or LMCAD & $2005-2007$ & 903 & 897 & $65 \pm 10$ & $65 \pm 10$ & NA & NA \\
\hline Tarantini and coworkers ${ }^{27}$ & OC & MVD, DM & 2004-2005 & 93 & 127 & $65 \pm 9$ & $67 \pm 7$ & $62 \pm 14$ & $62 \pm 14$ \\
\hline Toutouzas and coworkers ${ }^{28}$ & $\mathrm{OC}$ & LAD, DM & 2001-2006 & 39 & 38 & $59 \pm 13$ & $61 \pm 10$ & $48 \pm 7$ & $49 \pm 9$ \\
\hline $\begin{array}{l}\text { van Domburg and } \\
\text { coworkers }^{29}\end{array}$ & $\mathrm{OC}$ & MVD or LMCAD & 2002 & 798 & 275 & $62 \pm 11$ & $64 \pm 11$ & NA & NA \\
\hline Yang $^{30}$ & $\mathrm{OC}$ & MVD & 2003-2004 & 235 & 231 & $65 \pm 10$ & $65 \pm 10$ & $51 \pm 9$ & $50 \pm 11$ \\
\hline Yang and coworkers ${ }^{31}$ & $\mathrm{OC}$ & MVD & $2003-2005$ & 441 & 390 & $63 \pm 10$ & $63 \pm 8$ & $58 \pm 12$ & $53 \pm 14$ \\
\hline Yi and coworkers ${ }^{32}$ & $\mathrm{OC}$ & MVD, OPCAB & 2003-2005 & 194 & 194 & $63 \pm 10$ & $62 \pm 9$ & NA & NA \\
\hline
\end{tabular}

\section{METHODS \\ Search Strategy}

Electronic searches were performed in 6 databases from their inception to September 2009: Medline, Embase, Pubmed, Cochrane Central Register of Controlled Trials, Cochrane Database of Systematic Reviews, and Database of Abstracts of Review of Effectiveness. To achieve the maximum sensitivity of the search strategy and identify all trials comparing DESs and $\mathrm{CABG}$, we used appropriate free text and thesaurus terms, including "percutaneous coronary intervention," "coronary angioplasty," "coronary artery stenting," "drug-eluting stent," and "coronary artery bypass

TABLE 1. Summary of 25 comparative studies included in the present systematic review

$S D$, Standard deviation; $D E S$, drug-eluting stent; $C A B G$, coronary artery bypass grafting; $O C$, observational cohort; $D M$, diabetes mellitus; $N A$, not applicable; $L A D$, left anterior descending coronary artery; $M V D$, multivessel disease; $O P C A B$, off-pump coronary artery bypass; $L M C A D$, left main coronary artery disease; $L V$, left ventricle; $R C T$, randomized controlled trial. *Median. 
TABLE 2. Follow-up data of 25 comparative studies included in the present systematic review

\begin{tabular}{|c|c|c|c|c|}
\hline Reference & $\begin{array}{c}\text { Total patients enrolled } \\
\text { (DES/CABG) }\end{array}$ & $\begin{array}{l}\text { Total patients included } \\
\text { in study (DES/CABG) }\end{array}$ & $\begin{array}{c}\text { Follow-up } \\
\text { periods (mo) }\end{array}$ & $\begin{array}{l}\text { No. of patients at } \\
\text { last follow-up ( } \%)\end{array}$ \\
\hline Ben-Gal and coworkers ${ }^{9}$ & $518(176 / 342)$ & $172(86 / 86)$ & 18 & Not mentioned \\
\hline Ben-Gal and coworkers ${ }^{10}$ & $376(272 / 104)$ & $166(83 / 83)$ & 22 & Not mentioned \\
\hline Briguori and coworkers ${ }^{11}$ & 355 & $218(69 / 149)$ & 12 & $218(100 \%)$ \\
\hline Cheng and coworkers ${ }^{12}$ & Not mentioned & $363(94 / 216)$ & 27 & $325(90 \%)$ \\
\hline Chieffo and coworkers ${ }^{13}$ & Not mentioned & $249(107 / 142)$ & 12 & $249(100 \%)$ \\
\hline Domínguez-Franco and coworkers ${ }^{14}$ & Not mentioned & $270(128 / 142)$ & 24 & $263(97.4 \%)$ \\
\hline Gioia and coworkers ${ }^{15}$ & 230 & $220(128 / 92)$ & 15 & $220(100 \%)$ \\
\hline Hannan and coworkers ${ }^{16}$ & 29,095 & $17,400(9963 / 7437)$ & 18 & Not mentioned \\
\hline Hong and coworkers ${ }^{17}$ & Not mentioned & $189(119 / 70)$ & 6 & $184(97 \%)$ \\
\hline Javaid and coworkers ${ }^{18}$ & Not mentioned & $1680(979 / 701)$ & 12 & Not mentioned \\
\hline Kukreja and coworkers ${ }^{19}$ & 1812 & $682(289 / 206)$ & 36 & $682(100 \%)$ \\
\hline White and coworkers ${ }^{20}$ & Not mentioned & $173(50 / 123)$ & 6 & Not mentioned \\
\hline $\mathrm{Li}$ and coworkers ${ }^{21}$ & Not mentioned & $3720(1834 / 1886)$ & 36 & $3679(98.9 \%)$ \\
\hline Mäkikallio and coworkers ${ }^{22}$ & $6705 \dagger$ & $287(49 / 238)$ & 12 & Not mentioned \\
\hline Moshkovitz and coworkers ${ }^{23}$ & $522(168 / 354)$ & $232(116 / 116)$ & 12 & Not mentioned \\
\hline Palmerini and coworkers ${ }^{24}$ & 259 & $259(98 / 161)$ & 24 & $258(99.6 \%)$ \\
\hline Park and coworkers ${ }^{25}$ & Not mentioned & $3042(1547 / 1495)$ & 36 & Not mentioned \\
\hline Sanmartín and coworkers ${ }^{26}$ & Not mentioned & $341(96 / 245)$ & 12 & $334(98 \%)$ \\
\hline Serruys and coworkers ${ }^{6}$ & 4337 & $1800(903 / 897)$ & 12 & $1740(96.7 \%)$ \\
\hline Tarantini and coworkers ${ }^{27}$ & Not mentioned & $220(93 / 127)$ & 24 & $220(100 \%)$ \\
\hline Toutouzas and coworkers ${ }^{28}$ & $314(191 / 123)$ & $77(39 / 38)$ & 20 & $77(100 \%)$ \\
\hline van Domburg and coworkers ${ }^{29}$ & $1073^{*}$ & $1073(798 / 275)$ & 15 & $1073(100 \%)$ \\
\hline Yang and coworkers ${ }^{30}$ & Not mentioned & $466(235 / 231)$ & 25 & $436(93.6 \%)$ \\
\hline Yang and coworkers ${ }^{31}$ & 1212 & $831(441 / 390)$ & 12 & $795(95.7 \%)$ \\
\hline Yi and coworkers ${ }^{32}$ & $508(267 / 241)$ & $388(194 / 194)$ & 36 & $382(98.5 \%)$ \\
\hline
\end{tabular}

$D E S$, Drug-eluting stent; $C A B G$, coronary artery bypass grafting. ${ }^{*}$ Control group not included. $\dagger$ All patient undergoing coronary angiographic analysis.

grafting." The reference lists of all retrieved articles were reviewed for further identification of potentially relevant studies.

\section{Study Selection}

All studies assessing DESs versus CABG for coronary artery disease published in English were included. We excluded studies that did not include a comparative group that contained CABG as a form of intervention. When centers have published duplicate trials with accumulating numbers of patients or increased lengths of follow-up, only the most recent or complete reports were included for qualitative appraisal and meta-analysis. The publication types of letters, editorials, or reviews were excluded.

\section{Data Extraction and Critical Appraisal}

Two investigators (R.P. and T.D.Y.) independently reviewed each included article. Discrepancies between the 2 investigators were resolved by means of discussion and consensus with a senior investigator. The final results were reviewed by 3 senior investigators (M.K.W., P.G.B., and M.P.V.). Time points for analysis of outcomes were 30 days, 1 year, 2 years, and greater than 2 years. Data regarding the end points were extracted and reported separately as all-cause mortality at 30 days, all-cause mortality at 12 months, all-cause mortality at 24 months, all-cause stroke at last follow-up, 30-day myocardial infarction, myocardial infarction at last follow-up, repeat revascularization, 30-day MACCEs, and 12-month MACCEs. Where data were available, the following subgroups for analysis were proposed: vessels involved (left anterior descending coronary artery disease, left main coronary artery disease, and multivessel coronary artery disease), surgical intervention (standard CABG and off-pump coronary artery bypass), and comorbidities (diabetes). Because of the lack of a large number of patients to generate robust clinical conclusions, only multivessel disease was subject to separate analysis.

\section{Statistical Analysis}

Meta-analysis was performed by combining the results of reported incidence of morbidity, all-cause mortality, and repeat revascularization. The relative risk (RR) was used as a summary statistic. In this study both fixed- and random-effects models were tested. In a fixed-effects model it was assumed that treatment effect in each study was the same, whereas in a random-effects model it was assumed that there were variations between studies, and the calculated ratios thus had more conservative value. ${ }^{7} \chi^{2}$ Tests were used to study heterogeneity between trials. The $\mathrm{I}^{2}$ statistic was used to estimate the percentage of total variation across studies because of heterogeneity rather than chance. The $\mathrm{I}^{2}$ statistic can be calculated as follows: $\mathrm{I}^{2}=100 \% \times(\mathrm{Q}-\mathrm{df}) / \mathrm{Q}$, with $Q$ defined as Cochrane's heterogeneity statistics and $d f$ defined as degree of freedom. ${ }^{8}$ An $I^{2}$ value of greater than $50 \%$ was considered substantial heterogeneity. If there was substantial heterogeneity, the possible clinical and methodological reasons for this were explored qualitatively. In the present meta-analysis the results using the random-effects model were presented to take into account the possible clinical diversity and methodological variation among studies. Specific analyses considering confounding factors were not possible because raw data were not available. All $P$ values were 2 -sided. All statistical analysis was conducted with Review Manager Version 4.2 (Cochrane Collaboration, Software Update, Oxford, United Kingdom).

\section{RESULTS}

\section{Quantity and Quality of Trials}

A total of 616 references were identified through electronic database searches. After exclusion of duplicate or irrelevant references, 557 potentially relevant articles were retrieved for more detailed evaluation. An additional 3 


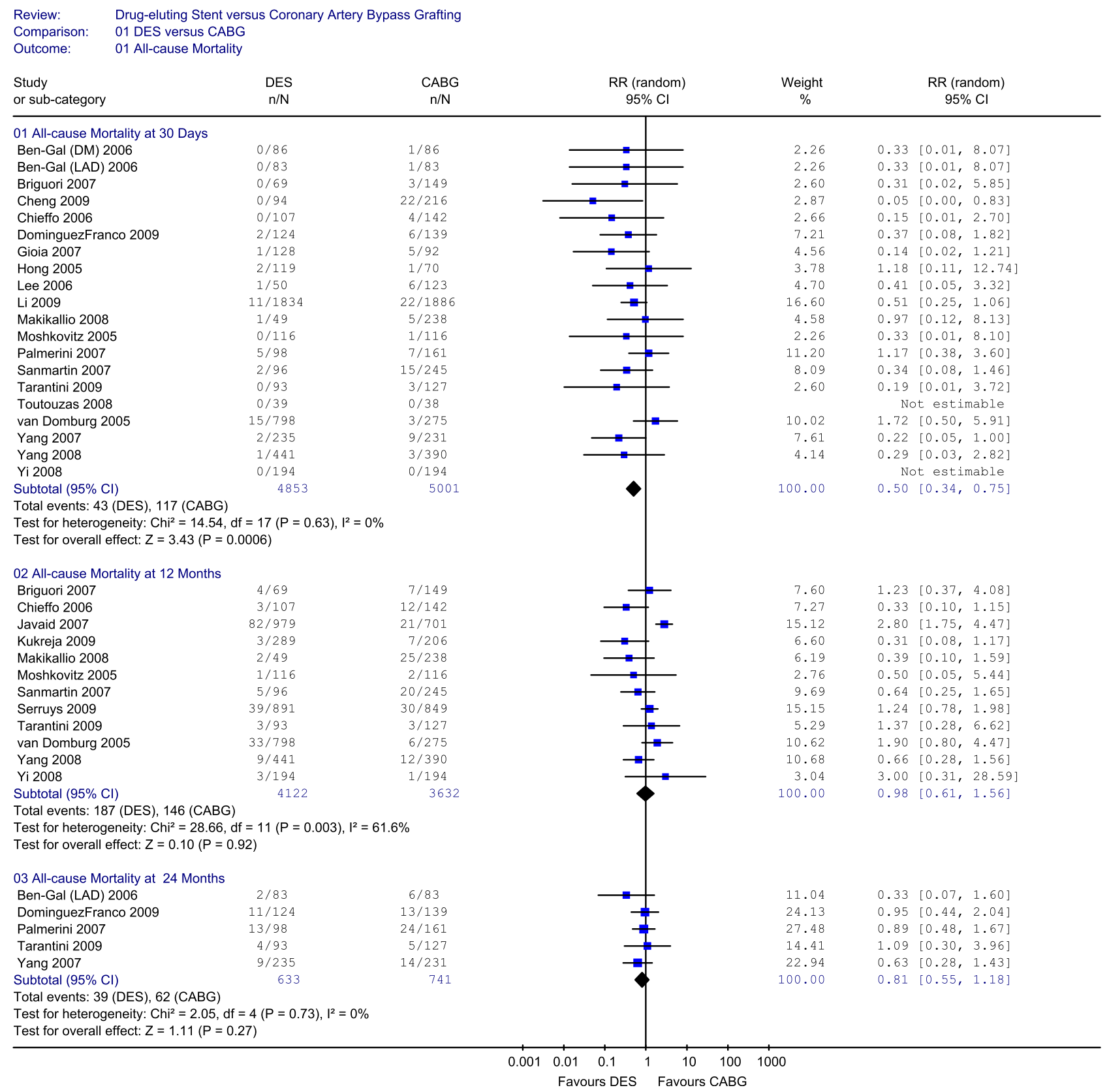

FIGURE 1. Forest plot of the relative risk $(R R)$ of all-cause mortality after drug-eluting stents $(D E S)$ versus coronary artery bypass grafting $(C A B G)$ for coronary artery disease. The estimate of the RR of each trial corresponds to the middle of the squares, and the horizontal line shows the $95 \%$ confidence interval $(C I)$. On each line, the numbers of events as a fraction of the total number randomized are shown for both treatment groups. For each subgroup, the sum of the statistics, along with the summary RR, is represented by the middle of the solid diamonds. A test of heterogeneity between the trials within a subgroup is given below the summary statistics.

potentially relevant reports were identified through scanning of reference lists. When inclusion and exclusion criteria were applied, 36 comparative studies remained for assessment. Four duplicate publications in which investigators reported initial accumulating numbers of participants or increased length of follow-up were excluded. Three studies were excluded because primary outcome data were not available. Four studies were withdrawn from the analysis because the treatment outcomes contained a mixture of DESs and BMSs. The final 25 most definitive reports $\left(1 \mathrm{RCT}^{6}\right.$ and 24 nonrandomized comparative studies $^{9-32}$ ) were included for appraisal and data extraction (Table 1). ${ }^{6,9-32}$

In these 25 studies 34,278 patients were compared, of whom 18,538 underwent PCI with DESs and 15,740 


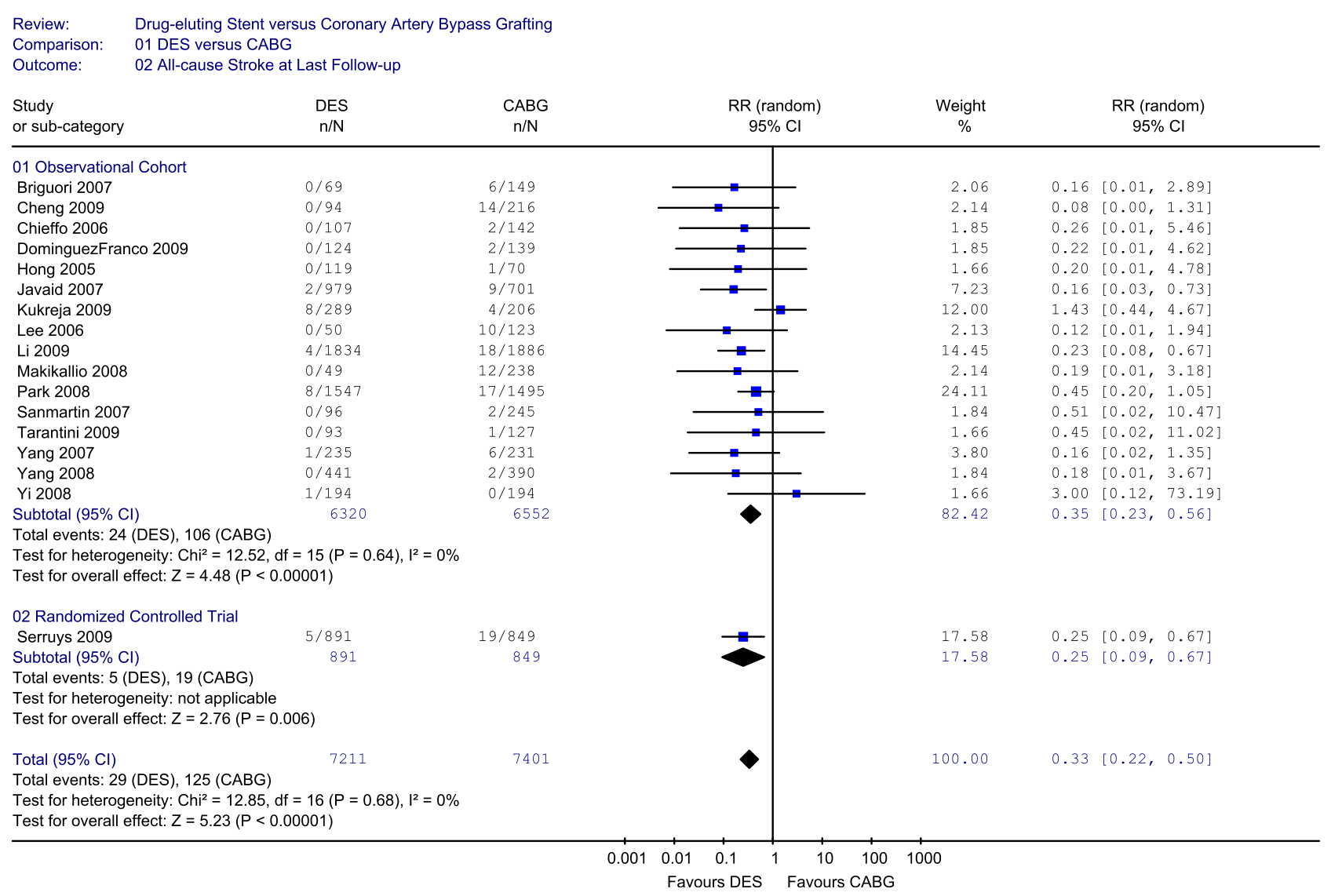

FIGURE 2. Forest plot of the relative risk $(R R)$ of all-cause stroke after drug-eluting stents $(D E S)$ versus coronary artery bypass grafting $(C A B G)$ for coronary artery disease. The studies were analyzed according to the type of morbidity and mortality. The estimate of the RR of each trial corresponds to the middle of the squares, and the horizontal line shows the $95 \%$ confidence interval $(C I)$. On each line, the numbers of events as a fraction of the total number randomized are shown for both treatment groups. For each subgroup, the sum of the statistics, along with the summary RR, is represented by the middle of the solid diamonds. A test of heterogeneity between the trials within a subgroup is given below the summary statistics.

underwent CABG. ${ }^{6,9-32}$ Seven studies focused on 1640 patients with left anterior descending coronary artery disease. ${ }^{10,11,14,17,19,23,28}$ Six studies compared DESs versus CABG in 1619 patients with left main coronary artery disease. ${ }^{12,13,20,22,24,26}$ Eleven studies assessed 28,693 patients with multivessel disease. ${ }^{11,14,16,18,19,21,25,27,30-32}$ Five studies focused on 950 diabetic patients with coronary artery disease. ${ }^{9,11,14,27,28}$ Three studies compared DESs versus off-pump coronary artery bypass surgery in 838 patients. ${ }^{11,23,32}$

This comparison represented a selected group of patients, in that not all patients who were initially screened underwent treatments (Table 2). ${ }^{6,9-32}$ Follow-up periods varied among studies and were mostly focused on short-term or midterm outcomes. Twenty-three studies ${ }^{6,9-16,18,19,21-32}$ had at least 1 year of follow-up, 9 studies ${ }^{12,14,19,21,24,25,27,30,32}$ had at least 2 years of follow-up, and 4 studies $^{19,21,25,32}$ provided 3-year follow-up data. Seventeen studies ${ }^{6,11-15,17,19,21,24,26-32}$ reported the numbers of patients available at the last followup, and this ranged from $90 \%$ to $100 \%$.

\section{Assessment of Morbidity and Mortality}

All-cause mortality was lower with DESs at 30 days $(0.9 \%$ vs $2.3 \%$; RR, $0.50 ; 95 \%$ confidence interval [CI], $\left.0.34-0.75 ; P<.001 ; \mathrm{I}^{2}=0 \%\right)$ and similar between DESs and CABG at 12 months ( $4.5 \%$ vs $4.0 \%$; RR, 0.98 ; $95 \%$ CI, $\left.0.61-1.56 ; P=.92 ; \mathrm{I}^{2}=61.6 \%\right)$ and 24 months $(6.2 \%$ vs $8.4 \%$; RR, $0.81 ; 95 \%$ CI, $0.55-1.18 ; P=.27$; $\mathrm{I}^{2}=0 \%$; Figure 1). Seventeen studies ${ }^{6,11-14,17-22,25-27,30-32}$ compared the incidence of stroke and demonstrated that DESs were associated with a lower incidence of stroke at last follow-up $(0.4 \%$ vs $1.7 \%$; RR, $0.33 ; 95 \%$ CI, 0.22-0.50; $P<.001$; Figure 2). There was no substantial heterogeneity among the randomized and nonrandomized studies $\left(\mathrm{I}^{2}=0 \%\right.$; heterogeneity $\left.P=.77\right)$. Composite results from 2 studies ${ }^{11,32}$ on DESs versus off-pump coronary artery bypass surgery showed that there was no significant difference in the accumulative stroke rate in 606 patients $(0.4 \%$ vs $1.7 \%$, respectively; RR, 0.64 ; $95 \%$ CI, $0.04-$ $11.45 ; \quad P=.76 ; \mathrm{I}^{2}=44.7 \%$ ). Seventeen studies $9,11-14,17,20,21,23,24,26-32$ showed similar accumulative 


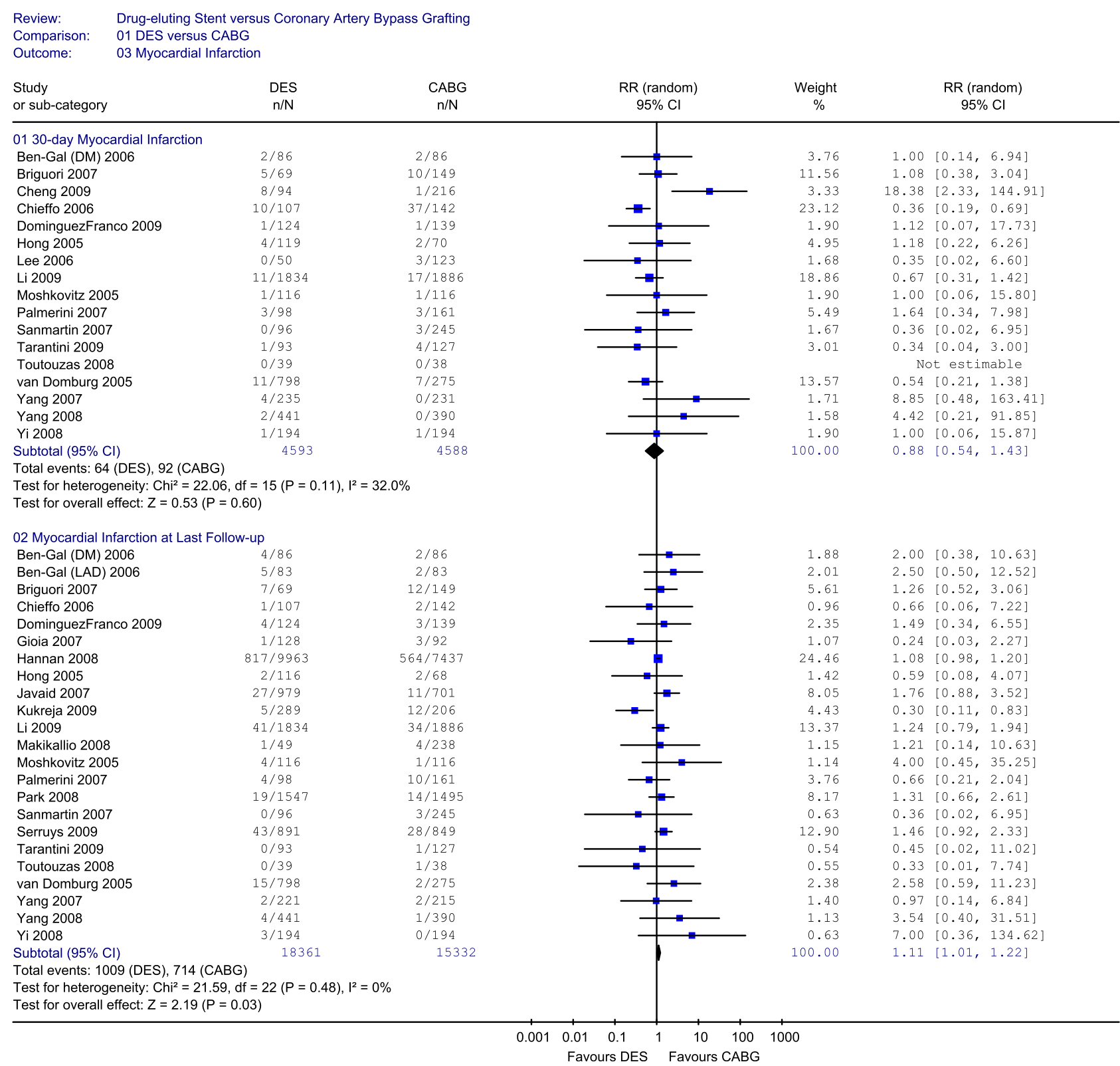

FIGURE 3. Forest plot of the relative risk $(R R)$ of myocardial infarction after drug-eluting stents $(D E S)$ versus coronary artery bypass grafting $(C A B G)$ for coronary artery disease. The estimate of the RR of each trial corresponds to the middle of the squares, and the horizontal line shows the $95 \%$ confidence interval $(C I)$. On each line, the numbers of events as a fraction of the total number randomized are shown for both treatment groups. For each subgroup, the sum of the statistics, along with the summary RR, is represented by the middle of the solid diamonds. A test of heterogeneity between the trials within a subgroup is given below the summary statistics.

incidence of 30-day myocardial infarction between DESs and CABG $(1.4 \%$ vs $2.0 \%$; RR, $0.88 ; 95 \%$ CI, $0.54-1.43$; $P=.60)$, and there was no substantial heterogeneity among the studies $\left(\mathrm{I}^{2}=32 \%\right.$; heterogeneity $P=.11$; Figure 3$)$. Twenty-three studies, ${ }^{6,9-11,13-19,21-32}$ compared the overall incidence of myocardial infarction at last follow-up and demonstrated that CABG was associated with a lower rate of postprocedural myocardial infarction $(5.5 \%$ vs $4.7 \%$; RR, 1.11 ;
$95 \% \mathrm{CI}, 1.01-1.22 ; P=.03)$, and there was no heterogeneity among the randomized and nonrandomized studies $\left(\mathrm{I}^{2}=0 \%\right.$; heterogeneity $P=.48$; Figure 3).

Twenty-three studies ${ }^{6,9-17,19,21-32}$ reported the incidence of repeat revascularization and demonstrated that DESs were associated with a higher rate of repeat revascularization $(22.2 \%$ vs $4.1 \%$; RR, $3.75 ; 95 \% \mathrm{CI}$, $2.80-5.02 ; P<.001 ; \mathrm{I}^{2}=77.0 \%$; Figure 4$)$. Subgroup 


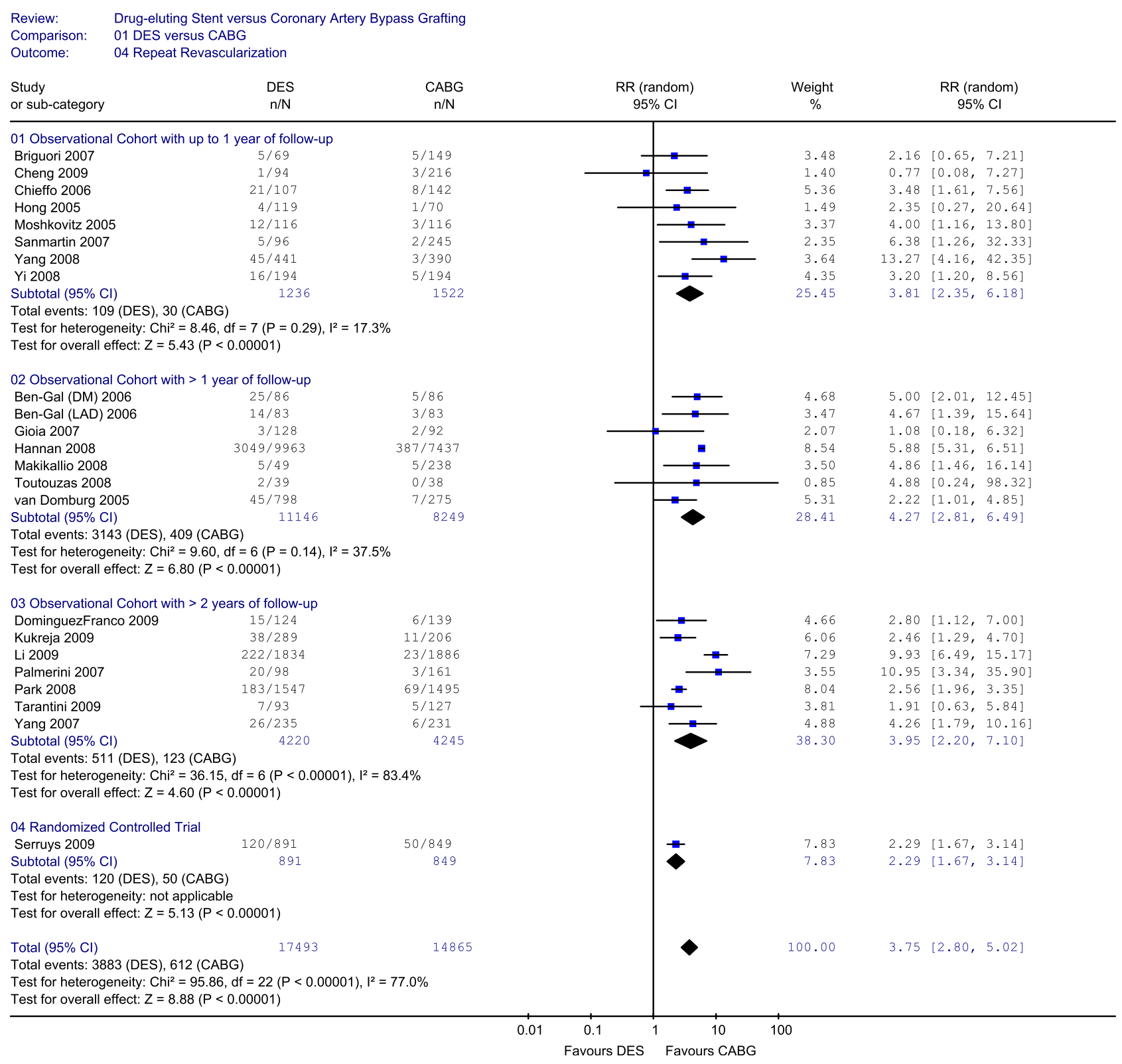

FIGURE 4. Forest plot of the relative risk $(R R)$ of repeat revascularization after drug-eluting stents $(D E S)$ versus coronary artery bypass grafting $(C A B G)$ for coronary artery disease. The estimate of the RR of each trial corresponds to the middle of the squares, and the horizontal line shows the $95 \%$ confidence interval $(C I)$. On each line, the numbers of events as a fraction of the total number randomized are shown for both treatment groups. For each subgroup, the sum of the statistics, along with the summary RR, is represented by the middle of the solid diamonds. A test of heterogeneity between the trials within a subgroup is given below the summary statistics.

analyses of 8 studies ${ }^{11-13,17,23,26,31,32}$ with 1 year of follow-up $(8.8 \%$ vs $2.0 \%$; RR, 3.81; 95\% CI, $2.35-$ $\left.6.18 ; P<.001 ; \mathrm{I}^{2}=17.3 \%\right), 7$ studies $9,10,15,16,22,28,29$ with 2 years of follow-up $(28.2 \%$ vs $5.0 \%$; RR, 4.27; 95\% CI, 2.81-6.49; $P<.001 ; \mathrm{I}^{2}=37.5 \%$ ), 7 studies ${ }^{14,19,21,24,25,27,30}$ with more than 2 years of follow-up (12\% vs $2.9 \%$; RR, 3.95; 95\% CI, 2.20-7.10; $P<.001$; $\left.\mathrm{I}^{2}=83.4 \%\right)$, and the $\mathrm{RCT}^{6}(13.5 \%$ vs $5.6 \%$; RR, 2.29; $95 \% \mathrm{CI}, 1.67-3.14 ; P<.001)$ all demonstrated that the rates of repeat revascularization were significantly higher with DESs compared with those seen after CABG (Figure 4).

Combined results showed that the accumulative incidence of MACCEs at 30 days was significantly lower with DESs (3.6\% vs 5.5\%; RR, 0.56; 95\% CI, 0.32-0.98; $P=.04$; $\mathrm{I}^{2}=51.3 \%$ ) but much higher with DESs at 12 months $(16.7 \%$ vs $10.5 \%$; RR, $1.61 ; 95 \%$ CI, 1.23-2.12; $P<.001 ; \mathrm{I}^{2}=68.2 \%$; Figure 5). 


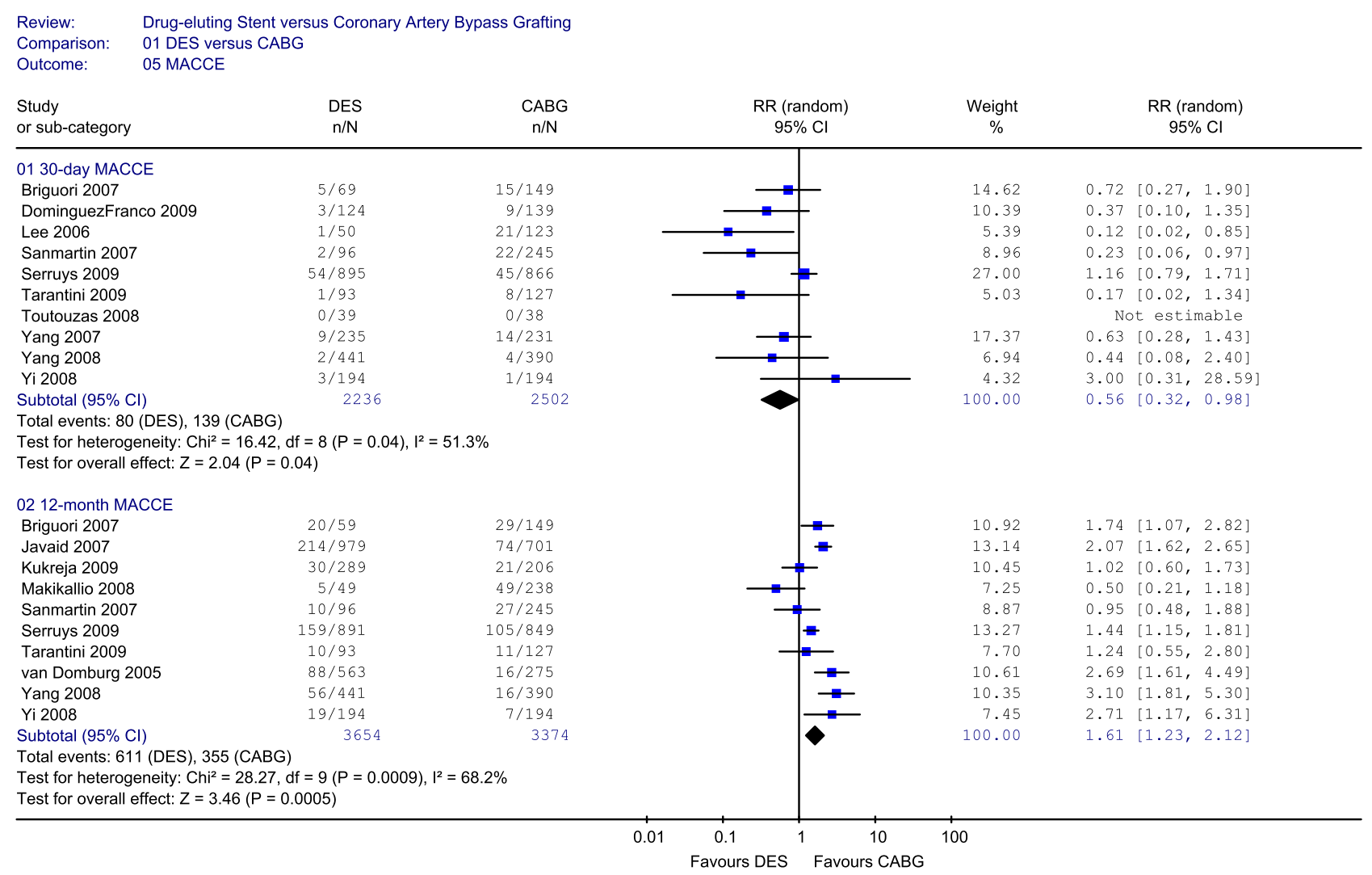

FIGURE 5. Forest plot of the relative risk $(R R)$ of major cardiac and cerebrovascular events (MACCE) after drug-eluting stents (DES) versus coronary artery bypass grafting $(C A B G)$ for coronary artery disease. The estimate of the RR of each trial corresponds to the middle of the squares, and the horizontal line shows the $95 \%$ confidence interval $(C I)$. On each line, the numbers of events as a fraction of the total number randomized are shown for both treatment groups. For each subgroup, the sum of the statistics, along with the summary RR, is represented by the middle of the solid diamonds. A test of heterogeneity between the trials within a subgroup is given below the summary statistics.

\section{Assessment of Multivessel Coronary Artery Disease}

In studies ${ }^{11,14,16,18,19,21,25,27,30-32}$ assessing patients with multivessel coronary artery disease, the accumulative rates of 30-day myocardial infarction $(0.8 \%$ vs $1.1 \%$; RR, $0.99 ; 95 \%$ CI, $0.51-1.51 ; P=.64 ; \mathrm{I}^{2}=0 \%$ ) and myocardial infarction at last follow-up $(5.9 \%$ vs $5.1 \%$; RR, $1.17 ; 95 \%$ CI, 0.92-1.49; $P=.19 ; \mathrm{I}^{2}=21.1 \%$ ) were similar between the DES group and the CABG group (Figure 6). The accumulative incidence of repeat revascularization was higher in the DES group compared with that seen in the CABG group $(24.4 \%$ vs $4.2 \%$; RR, $4.03 ; 95 \% \mathrm{CI}$, $\left.2.70-6.01 ; P<.001 ; \mathrm{I}^{2}=84.4 \%\right)$. The accumulative incidence of MACCEs was lower in the DES group compared with that in the CABG group at 30 days $(2.0 \%$ vs $4.1 \%$; RR, $0.58 ; 95 \%$ CI, $0.35-0.97 ; P=.04 ; \mathrm{I}^{2}=0 \%$ ) but was higher in the DES group at 12 months $(16.1 \%$ vs $8.6 \%$; RR, 1.74; 95\% CI, 1.24-2.44; $\left.P=.001 ; \mathrm{I}^{2}=55.1 \%\right)$.

\section{DISCUSSION}

Since 2002, DESs have been shown to reduce repeat revascularization rates without affecting the short- and long- term safety of the treatment. ${ }^{4,33}$ The recently published SYNTAX trial demonstrated that in patients with triplevessel or left main coronary artery disease at 12 months, the rates of death and myocardial infarction were similar between the DES and CABG groups, and DESs were associated with a lower rate of stroke $(0.6 \%$ vs $2.2 \%$, $P=.003){ }^{6}{ }^{6}$ However, for the primary end point, 12 -month MACCEs, the noninferiority of use of DESs compared with $\mathrm{CABG}$ was not demonstrated; CABG was proved to be superior $(17.8 \%$ vs $12.4 \%, P=.002){ }^{6}$ Other largescale RCTs, such as Future Revascularization Evaluation in Patients with Diabetes: Optimal Management of Multivessel Disease and Coronary Artery Revascularization in Diabetics, are ongoing.

The present meta-analysis demonstrated the following key findings: the accumulative incidences of all-cause mortality at 12 and 24 months and 30-day myocardial infarction were similar between the 2 groups. DESs were associated with lower rates of all-cause mortality at 30 days, stroke, and 30-day MACCEs; however, the CABG group had a lower incidence of overall myocardial infarction at last follow-up, repeat revascularization, and 12-month 


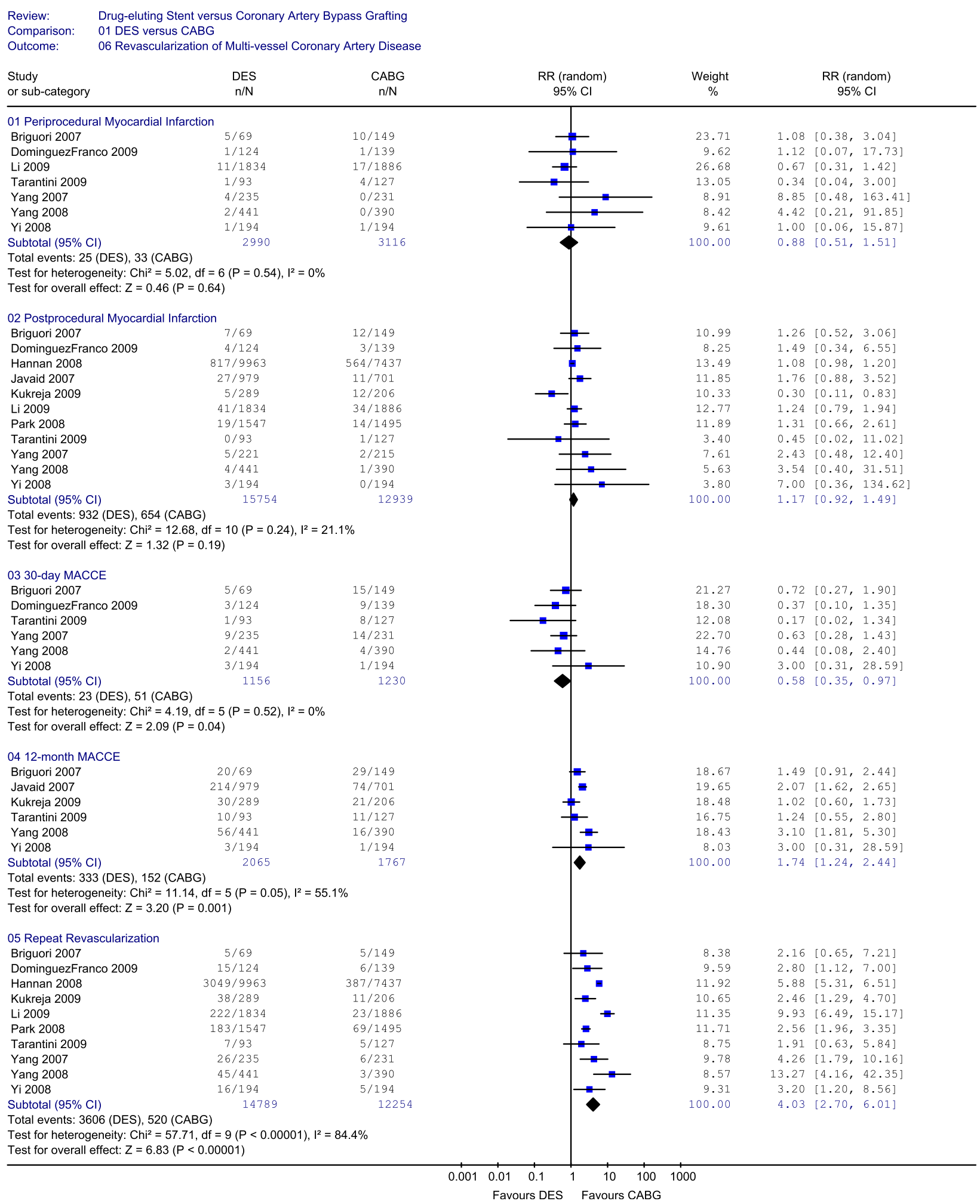

FIGURE 6. Forest plot of the relative risk $(R R)$ of 30-day myocardial infarction, myocardial infarction at last follow-up, repeat revascularization, and 30-day and 12-month major cardiac and cerebrovascular events (MACCE) after drug-eluting stents $(D E S)$ versus coronary artery bypass grafting $(C A B G)$ for multivessel coronary artery disease. The estimate of the RR of each trial corresponds to the middle of the squares, and the horizontal line shows the $95 \%$ confidence interval $(C I)$. On each line, the numbers of events as a fraction of the total number randomized are shown for both treatment groups. For each subgroup, the sum of the statistics, along with the summary RR, is represented by the middle of the solid diamonds. A test of heterogeneity between the trials within a subgroup is given below the summary statistics. 
MACCEs. Subgroup analysis on patients with multivessel coronary artery disease showed similar results. The present meta-analysis emphasized that in assessing use of DESs versus $\mathrm{CABG}$, one must consider the relative merits of the $\mathrm{CABG}$ procedure with lasting benefits against less-invasive DESs with traditionally higher rates of reintervention.

Although procedural success rates are high and periprocedural complication rates are relatively low with PCI, rates of restenosis, which might require reintervention, have traditionally been a significant limitation of coronary stenting. The advent of antiproliferative DESs has dramatically reduced target-lesion and target-vessel restenosis and the incidence of repeat revascularization compared with BMSs. ${ }^{4,33,34}$ However, there is still a lack of high-level clinical evidence on the use of DESs for patients with multivessel disease. Because of the aging population in Western countries and a growing incidence of coronary artery disease in the developing world, multivessel revascularization is increasing. Most of these patients have significant comorbidities. Hannan and colleagues ${ }^{16}$ identified 17,400 patients with multivessel disease from a large-scale registry and demonstrated that CABG was associated with lower 18-month rates of repeat revascularization, death, and/or myocardial infarction compared with DESs. The present meta-analysis on both randomized and nonrandomized comparative studies confirmed that CABG was still more effective than DESs in reducing 12-month MACCEs and the need for target-vessel revascularization and confirmed the advantages of CABG as the standard of care for patients with multi-vessel coronary artery disease in real-world clinical practice.

It needs to be acknowledged that (1) the data included in the present meta-analysis were mostly extrapolated from nonrandomized studies, which are subject to selection bias; (2) this comparison represented a subset of patients who were initially enrolled or screened for treatments; and (3) although not clearly stated in each study, from the SYNTAX registry, we know that at least one third of patients undergoing $\mathrm{CABG}$ are ineligible for PCI because of complexity of lesions, and in the absence of comparison of the baseline characteristics among all the studies, it is reasonable to assume that there were confounding factors in allocating patients to undergo either CABG or PCI and patients who underwent $\mathrm{CABG}$ had more complex disease. In the current meta-analysis the accumulative results from the observational cohorts demonstrated concordant results to the SYNTAX trial, ${ }^{6}$ and this might reflect the outcomes in a more heterogeneous group of patients in clinical practice. As with any meta-analysis, the conclusions drawn from such data are subject to the limitations of the original included studies and the differences in patients and techniques among different centers. The validity of the effect estimates in the studies depends on factors such as the recruitment of inception cohorts, patient selection criteria, and length of follow-up. Clinical follow-up to date is still limited at the short-term to midterm threshold, which might capture most of the repeat procedures needed with stent technology, but does not have sufficient follow-up to capture even half of the graft failures, which would require 10 years. It is understood that the survival benefit of CABG could not be fully demonstrated when most studies only had limited follow-up. Large-scale RCTs with long follow-up will provide complementary data comparing DESs and CABG, especially in the context of late stent thrombosis, but the rate of technological advancement is likely to make the results of such trials obsolete.

Although DESs are associated with less periprocedural risks, the current literature suggests that DESs are inferior to $\mathrm{CABG}$ in terms of a higher incidence of postprocedural myocardial infarction, repeat revascularization, and 12month MACCEs.

We thank Professor Deborah Black for statistical analysis.

\section{References}

1. Takagi H, Kawai N, Umemoto T. Meta-analysis of four randomized controlled trials on long-term outcomes of coronary artery bypass grafting versus percutaneous coronary intervention with stenting for multivessel coronary artery disease. Am J Cardiol. 2008;101:1259-62.

2. Mercado N, Wijns W, Serruys PW, Sigwart U, Flather MD, Stables RH, et al. One-year outcomes of coronary artery bypass graft surgery versus percutaneous coronary intervention with multiple stenting for multisystem disease: a metaanalysis of individual patient data from randomized clinical trials. $J$ Thorac Cardiovasc Surg. 2005;130:512-9.

3. Daemen J, Boersma E, Flather M, Booth J, Stables R, Rodriguez A, et al. Longterm safety and efficacy of percutaneous coronary intervention with stenting and coronary artery bypass surgery for multivessel coronary artery disease: a metaanalysis with 5-year patient-level data from the ARTS, ERACI-II, MASS-II, and SoS trials. Circulation. 2008;118:1146-54.

4. Stettler C, Wandel S, Allemann S, Kastrati A, Morice MC, Schömig A, et al. Outcomes associated with drug-eluting and bare-metal stents: a collaborative network meta-analysis. Lancet. 2007;370:937-48.

5. Bavry AA, Kumbhani DJ, Helton TJ, Borek PP, Mood GR, Bhatt DL. Late thrombosis of drug-eluting stents: a meta-analysis of randomized clinical trials. $\mathrm{Am}$ J Med. 2006;119:1056-61.

6. Serruys PW, Morice MC, Kappetein AP, Colombo A, Holmes DR, Mack MJ, et al. Percutaneous coronary intervention versus coronary-artery bypass grafting for severe coronary artery disease. N Engl J Med. 2009;360:961-72.

7. DerSimonian R, Laird N. Meta-analysis in clinical trials. Control Clin Trials. 1986;7:177-88.

8. Higgins J, Thompson S. Quantifying heterogeneity in a meta-analysis. Stat Med. 2002;21:1539-58.

9. Ben-Gal Y, Moshkovitz Y, Nesher N, Uretzky G, Braunstein R, Hendler A, et al. Drug-eluting stents versus coronary artery bypass grafting in patients with diabetes mellitus. Ann Thorac Surg. 2006;82:1692-7.

10. Ben-Gal Y, Mohr R, Braunstein R, Finkelstein A, Hansson N, Hendler A, et al Revascularization of left anterior descending artery with drug-eluting stents: comparison with minimally invasive direct coronary artery bypass surgery. Ann Thorac Surg. 2006;82:2067-71.

11. Briguori C, Condorelli G, Airoldi F, Focaccio A, D'Andrea D, Cannavale M, et al Comparison of coronary drug-eluting stents versus coronary artery bypass grafting in patients with diabetes mellitus. Am J Cardiol. 2007;99:779-84.

12. Cheng CI, Lee FY, Chang JP, Hsueh SK, Hsieh YK, Fang CY, et al. Long-term outcomes of intervention for unprotected left main coronary artery stenosis: coronary stenting vs coronary artery bypass grafting. Circ J. 2009;73:705-12.

13. Chieffo A, Morici N, Maisano F, Bonizzoni E, Cosgrave J, Montorfano M, et al. Percutaneous treatment with drug-eluting stent implantation versus bypass surgery for unprotected left main stenosis: a single-center experience. Circulation 2006; 113:2542-7. 
14. Domínguez-Franco AJ, Jiménez-Navarro MF, Hernández-García JM, AlonsoBriales JH, Linde-Estrella AL, Pérez-González O, et al. Comparison of medium-term outcomes obtained with drug-eluting stents and coronary artery bypass grafts in an unselected population of diabetic patients with multivessel coronary disease. Propensity score analysis. Rev Esp Cardiol. 2009;62:491-500.

15. Gioia G, Matthai W, Gillin K, Dralle J, Benassi A, Gioia MF, et al. Revascularization in severe left ventricular dysfunction: outcome comparison of drugeluting stent implantation versus coronary artery by-pass grafting. Catheter Cardiovasc Interv. 2007;70:26-33

16. Hannan EL, Wu C, Walford G, Culliford AT, Gold JP, Smith CR, et al. Drugeluting stents vs. coronary-artery bypass grafting in multivessel coronary disease. N Engl J Med. 2008;358:331-41.

17. Hong SJ, Lim DS, Seo HS, Kim YH, Shim WJ, Park CG, et al. Percutaneous coronary intervention with drug-eluting stent implantation vs. minimally invasive direct coronary artery bypass (MIDCAB) in patients with left anterior descending coronary artery stenosis. Catheter Cardiovasc Interv. 2005;64:75-81.

18. Javaid A, Steinberg DH, Buch AN, Corso PJ, Boyce SW, Pinto Slottow TL, et al. Outcomes of coronary artery bypass grafting versus percutaneous coronary intervention with drug-eluting stents for patients with multivessel coronary artery disease. Circulation. 2007;116(suppl):I200-6.

19. Kukreja N, Serruys PW, De Bruyne B, Colombo A, Macaya C, Richardt G, et al. Sirolimus-eluting stents, bare metal stents or coronary artery bypass grafting for patients with multivessel disease including involvement of the proximal left anterior descending artery: analysis of the Arterial Revascularization Therapies study part 2 (ARTS-II). Heart. 2009;95:1061-6.

20. White AJ, Kedia G, Mirocha JM, Lee MS, Forrester JS, Morales WC, et al. Comparison of coronary artery bypass surgery and percutaneous drug-eluting stent implantation for treatment of left main coronary artery stenosis. JACC Cardiovasc Interv. 2008;1:236-45.

21. Li Y, Zheng Z, Xu B, Zhang S, Li W, Gao R, et al. Comparison of drug-eluting stents and coronary artery bypass surgery for the treatment of multivessel coronary disease: three-year follow-up results from a single institution. Circulation. 2009;119:2040-50.

22. Mäkikallio TH, Niemelä M, Kervinen K, Jokinen V, Laukkanen J, Ylitalo I, et al. Coronary angioplasty in drug eluting stent era for the treatment of unprotected left main stenosis compared to coronary artery bypass grafting. Ann Med. 2008;40: 437-43.

23. Moshkovitz Y, Mohr R, Braunstein R, Zivi E, Uretzky G, Ben-Gal Y, et al. Revascularization of left anterior descending coronary artery in patients with single and multivessel disease: comparison between off-pump internal thoracic artery and drug-eluting stent. Chest. 2005;128:804-9.
24. Palmerini T, Barlocco F, Santarelli A, Bacchi-Reggiani L, Savini C, Baldini E, et al. A comparison between coronary artery bypass grafting surgery and drug eluting stent for the treatment of unprotected left main coronary artery disease in elderly patients (aged $>$ or $=75$ years). Eur Heart $J$. 2007;28:2714-9.

25. Park DW, Yun SC, Lee SW, Kim YH, Lee CW, Hong MK, et al. Long-term mortality after percutaneous coronary intervention with drug-eluting stent implantation versus coronary artery bypass surgery for the treatment of multivessel coronary artery disease. Circulation. 2008;117:2079-86.

26. Sanmartín M, Baz JA, Claro R, Asorey V, Durán D, Pradas G, et al. Comparison of drug-eluting stents versus surgery for unprotected left main coronary artery disease. Am J Cardiol. 2007;100:970-3.

27. Tarantini G, Ramondo A, Napodano M, Favaretto E, Gardin A, Bilato C, et al. PCI versus $\mathrm{CABG}$ for multivessel coronary disease in diabetics. Catheter Cardiovasc Interv. 2009;73:50-8.

28. Toutouzas K, Patsa C, Vaina S, Tsiamis E, Vavuranakis M, Stefanadi E, et al. A preliminary experience report: drug-eluting stents versus coronary artery bypass surgery in patients with a single lesion in the proximal left anterior descending artery suffering from diabetes mellitus and chronic stable angina. Hellenic J Cardiol. 2008;49:65-71.

29. van Domburg RT, Lemos PA, Takkenberg JJ, Liu TK, van Herwerden LA, Arampatzis CA, et al. The impact of the introduction of drug-eluting stents on the clinical practice of surgical and percutaneous treatment of coronary artery disease. Eur Heart J. 2005;26:675-81.

30. Yang ZK, Shen WF, Zhang RY, Kong Y, Zhang JS, Hu J, et al. Coronary artery bypass surgery versus percutaneous coronary intervention with drug-eluting stent implantation in patients with multivessel coronary disease. J Interv Cardiol. 2007; 20:10-6.

31. Yang JH, Gwon HC, Cho SJ, Hahn JY, Choi JH, Choi SH, et al. Comparison of coronary artery bypass grafting with drug-eluting stent implantation for the treatment of multivessel coronary artery disease. Ann Thorac Surg. 2008;85:65-70.

32. Yi G, Youn YN, Yoo KJ, Hong YS. Comparison of off-pump coronary artery bypass grafting with percutaneous coronary intervention versus drug-eluting stents for three-vessel coronary artery disease. Ann Thorac Surg. 2008;86: 1438-43.

33. Stone GW, Moses JW, Ellis SG, Schofer J, Dawkins KD, Morice MC, et al. Safety and efficacy of sirolimus- and paclitaxel-eluting coronary stents. $N$ Engl J Med. 2007;356:998-1008.

34. Kirtane AJ, Gupta A, Iyengar S, Moses JW, Leon MB, Applegate R, et al. Safety and efficacy of drug-eluting and bare metal stents: comprehensive meta-analysis of randomized trials and observational studies. Circulation. 2009;119:3198-206 